\title{
Effect of Temperature on the Corrosion Inhibition of 3-Phosphonopropionic Acid on Mild Steel in Groundwater
}

\author{
V. MANIVANNAN* and N. CHITHRALEKHA ${ }^{\mathrm{a}}$ \\ Department of Chemistry, Paavai College of Engineering, Namakkal-637 018, \\ Tamilnadu, India \\ ${ }^{a}$ Department of Physics, Mahendra College of Engineering, Salem-637106, \\ Tamilnadu, India \\ manivannanv1971@gmail.com
}

Received 15 June 2012 / Accepted 8 July 2012

\begin{abstract}
The inhibition and the effect of temperature and concentration of 3-phosphonopropionic acid (3-PPA) on the corrosion of mild steel in groundwater was investigated by weight loss and potentiodynamic polarization experiments at temperatures ranging from $30^{\circ} \mathrm{C}$ to $60{ }^{\circ} \mathrm{C}$. The studied inhibitor concentrations were between $6 \mathrm{ppm}$ to $18 \mathrm{ppm}$. The percentage inhibition increased with the increase of the concentration of the inhibitor. The percentage inhibition reached about $66.2 \%$ at the concentration of $12 \mathrm{ppm}$ at $30{ }^{\circ} \mathrm{C}$. On the other hand the percentage inhibition decreased with the increase of temperature.
\end{abstract}

Keywords: Corrosion, Inhibitor, 3- Phosphonopropionic acid, Polarization measurements

\section{Introduction}

Water is the most commonly used cooling fluid to remove unwanted heat from heat transfer surfaces. If absolutely pure water was used in the cooling system, none of the problems would exist. Unfortunately, waters contain dissolved and suspended solids, dissolved and suspended organic matters and dissolved gases. Finally, in cooling water system, with longer holding times at higher temperatures in the presence of higher dissolved solids concentrations, produces more severe corrosion and scale ${ }^{1}$. Many inhibitors have been used in cooling water systems in order to solve this problems ${ }^{2-5}$. Particularly, fatty amine associated with phosphonocarboxylic acid salts, hydroxyethane diphosphonic acid (HEDP) and hydroxyphosphonoacetic acid (HPA) were the standard corrosion inhibitors ${ }^{6-8}$. Other researchers concentrated their studies on synergy between molybdate and others organic and inorganic compounds for corrosion inhibition for water treatment in cooling systems ${ }^{9}$. Gluconate and the gluconic acid are known to be effective non-toxic inhibitors for iron and mild steel in cooling water systems ${ }^{10,11}$. Sodium, calcium and zinc salts of gluconic acid have been reported to be successful inhibitors against the corrosion of tin, iron and of the mild steel in near neutral media ${ }^{12}$. Quaternary phosphonium compounds are known to 
effectively control bacterial growth in a number of systems ${ }^{13-14}$ and have significant advantage of being "environmentally friendly". Their benefits include low toxicity, rapid breakdown in the environment (through hydrolysis, oxidation, photo-degradation and biodegradation) and no or little bioaccumulation.

In the present study, 3-phosphonopropionic acid (3-PPA) has been evaluated as a corrosion inhibitor for mild steel in more corrosive groundwater solutions using weight loss and potentiodynamic polarisation measurements.

\section{Experimental}

Mild steel samples with the composition C- $0.13 \%$, P- $0.032 \%$, Si- $0.014 \%, \mathrm{~S}-0.025 \%$, Mn$0.48 \%$ and $\mathrm{Fe}$ were used. For each electrochemical study, specimens of size $1.0 \mathrm{~cm} \times 1.0 \mathrm{~cm}$ $x 0.3 \mathrm{~cm}$ were cut, embedded in epoxy resin and mechanically polished with silicon carbide papers (from grades 120 to 1,200 ) followed by then washing with double distilled water, degreasing with acetone and drying at room temperature. For weight loss measurements metal specimens of $4.0 \mathrm{~cm} \times 2.0 \mathrm{~cm} \times 0.2 \mathrm{~cm}$ dimension were used. A sample that was corrosive in nature was chosen as the test solution for all the experiments; the typical analysis of this electrolyte is as follows: $\mathrm{pH}-6.78$, Temperature $-28{ }^{\circ} \mathrm{C}$, Total hardness 332 ppm, Alkalinity - 316 ppm, TDS - 316 ppm.

\section{Weight loss measurements}

Mild steel specimens in triplicate were immersed in groundwater at room temperature with and without the inhibitor concentration for 7 days at $30{ }^{\circ} \mathrm{C}$. The specimens were removed, rinsed in double distilled water and acetone then kept in a desiccator. Then the weight loss was determined in order to calculate the inhibition efficiency using the formula,

$$
\operatorname{IE}(\%)=\frac{\mathrm{Wo}_{0}-\mathrm{Wi}}{\mathrm{Wo}} \times 100
$$

Where, $\mathrm{W}_{0}$ and $\mathrm{W}_{\mathrm{i}}$ are the weight loss in the absence and presence of inhibitor respectively.

\section{Electrochemical studies}

All the electrochemical measurements presented in this study were performed using the Electrochemical Workstation (Model No: CHI 760, CH Instruments, USA). Prior to the electrochemical measurements, the metal specimens were prepared according to the procedure described above. All the experiments were carried out at room temperature with groundwater as an electrolyte. The platinum electrode and saturated calomel electrode (SCE) were used as auxiliary and reference electrodes respectively and the working electrodes constitute mild steel specimens of $1 \mathrm{~cm}^{2}$ area. In order to minimize ohmic potential drop the tip of the reference electrode is positioned very close proximity to the working electrode surface by the use of fine Luggin capillary and the remaining uncompensated resistance was also reduced by electrochemical workstation. Potentiodynamic polarization curves were also obtained at different temperatures $\left(30^{\circ} \mathrm{C}\right.$. to $\left.60^{\circ} \mathrm{C}\right)$ to observe the temperature dependence of inhibition effects.

Potentiodynamic polarization studies were carried out at a scan rate of $0.1 \mathrm{mV} / \mathrm{s}$. In all cases the OCP was established first and then the polarization measurement was carried out. The polarization curves for mild steel specimens in the test solution with and without various concentrations of inhibitors were recorded from -1200 to $0 \mathrm{mV}$. 


\section{Results and Discussion}

\section{Weight loss measurements}

Data recorded in Table 1 represent the effect of concentration of the phosphono derivative (3-PPA) on the weight loss of mild steel in groundwater as the corrosive medium at $30^{\circ} \mathrm{C}$. It is obvious that the loss in weight in the presence of inhibitor is lower than that in its absence and mostly decreases as the concentrations of 3-PPA increase up to the optimum level. The corrosion rate was found to decrease the maximum value of $2.2 \mathrm{mpy}$ at the optimum concentration of $12 \mathrm{ppm}$ and its corresponding inhibition efficiency value was found to be $65.9 \%$.

Table 1. Weight loss measurements of mild steel in groundwater in the absence and presence of various concentrations of 3 -PPA at $30^{\circ} \mathrm{C}$

\begin{tabular}{cccc}
\hline Inhibitor & $\begin{array}{c}\text { Inhibitor conc. } \\
\text { ppm }\end{array}$ & $\begin{array}{c}\text { Corrosion } \\
\text { rate, mpy }\end{array}$ & $\begin{array}{c}\text { Inhibition } \\
\text { efficiency, \% }\end{array}$ \\
\hline Blank & - & 6.6 & - \\
& 6 & 4.05 & 38.63 \\
& 8 & 3.97 & 39.84 \\
3-PPA & 10 & 2.96 & 55.15 \\
& 12 & 2.2 & 65.90 \\
& 14 & 2.85 & 56.81 \\
& 16 & 3.39 & 48.63 \\
18 & 3.75 & 43.18 \\
\hline
\end{tabular}

\section{Potentiodynamic polarization measurements}

From the polarization curves, the corrosion current density $\left(\mathrm{i}_{\text {corr }}\right)$ was determined by Tafel extrapolation method and the corrosion rates were determined from $i_{\text {corr }}$ values. The anodic and cathodic potentiodynamic polarization curves for mild steel in groundwater medium in the absence and presence of different concentrations of 3-PPA at $30{ }^{\circ} \mathrm{C}$ is represented in Figure 1. From the figure depicted, it is evident that an appreciable decrease in both cathodic and anodic current was observed. Addition of 3-PPA to the test solution showed a shift in corrosion potential towards anodic direction corresponding to the predominant control of anodic reaction. The corrosion current was decreased considerably in the presence of 3-PPA. The value of corrosion rate of mild steel in the presence of inhibitor was much smaller than that in the absence of an inhibitor. In the presence of 3-PPA, the inhibition efficiency was about $66.2 \%$ and the corrosion rate was found to be $1.92 \mathrm{mpy}$ at the optimum concentration of $12 \mathrm{ppm}$.

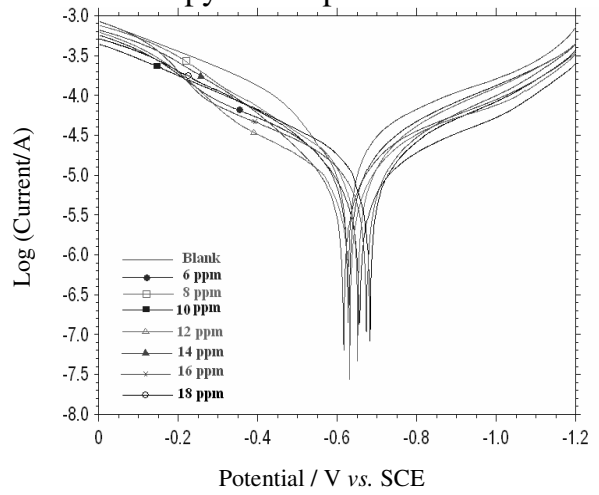

Figure 1. Potentiodynamic polarization curves of mild steel in groundwater in the absence and presence of various concentrations of 3 -PPA at $30{ }^{\circ} \mathrm{C}$ 
Figure 2-4 depicts the potentiodynamic polarization curves obtained for mild steel in groundwater both in the absence and presence of 3PPA at $40-60{ }^{\circ} \mathrm{C}$. It can be seen from the experimental results that the presence of 3-PPA resulted in a slight shift of the corrosion potential towards the anodic direction in comparison to the results obtained in the absence of the inhibitor. Moreover at this temperatures, both the anodic and cathodic current densities decreased indicating that 3-PPA suppressed both the anodic and cathodic reactions, although mainly the anodic one. The calculated values $\mathrm{E}_{\text {corr }}, \mathrm{i}_{\text {corr }}$ and inhibition efficiency were found to be $-587 \mathrm{mV}$, $9.32 \mu \mathrm{A} \mathrm{cm}^{-2}$ and $53.7 \%$ respectively for 3-PPA at the optimum concentration of $12 \mathrm{ppm}$ at $60^{\circ} \mathrm{C}$. These values are indicative of the fact that there is an increase in the extent of corrosion in mild steel due to the temperature raise from 30 to $60^{\circ} \mathrm{C}$. All the values are recorded in Table 2 .

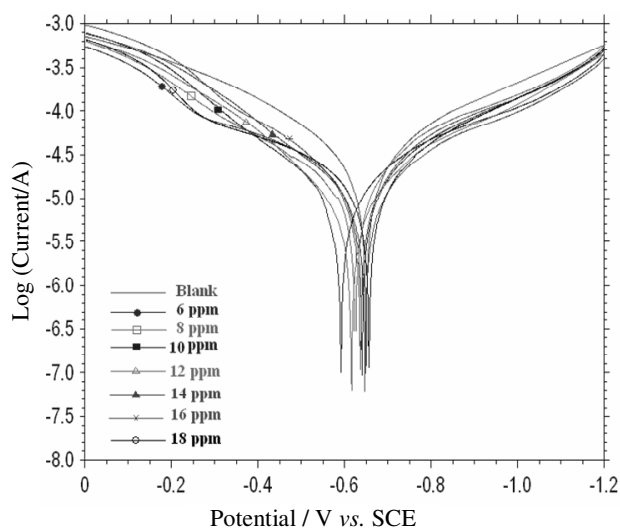

Figure 2. Potentiodynamic polarization curves of mild steel in groundwater in the absence and presence of various concentrations of 3-PPA at $40{ }^{\circ} \mathrm{C}$

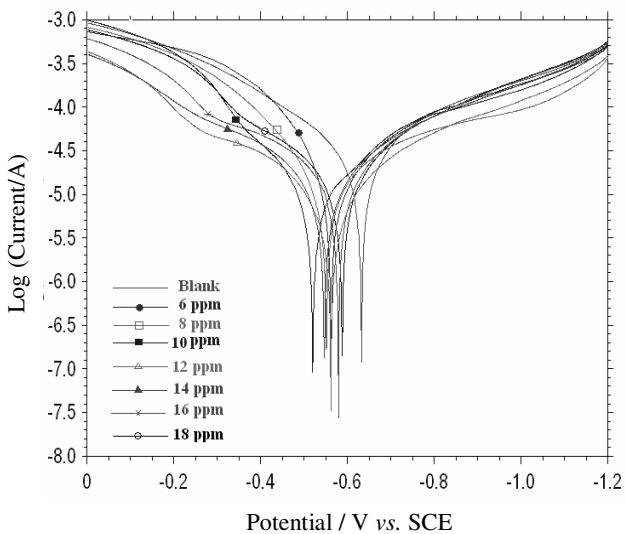

Figure 3. Potentiodynamic polarization curves of mild steel in groundwater in the absence and presence of various concentrations of 3-PPA at $50{ }^{\circ} \mathrm{C}$

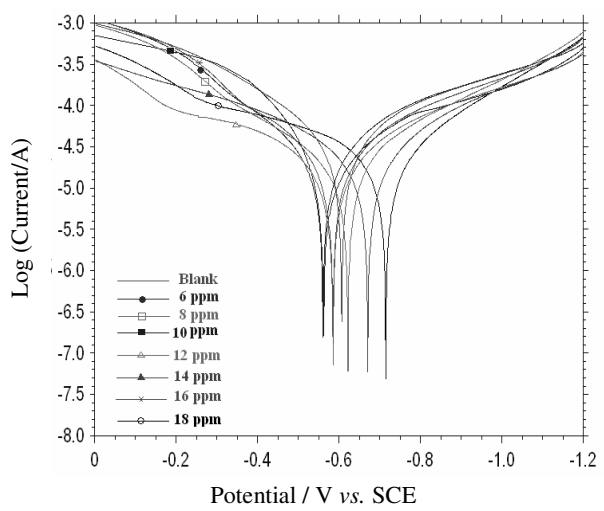

Figure 4. Potentiodynamic polarization curves of mild steel in groundwater in the absence and presence of various concentrations of 3-PPA at $60{ }^{\circ} \mathrm{C}$

\section{Effect of temperature}

It has been observed that the corrosion current density ( $\left.\mathrm{I}_{\text {corr }}\right)$ increased with increasing temperature. The $\mathrm{i}_{\text {corr }}$ increased with increasing temperature, both in uninhibited and inhibited solutions. Corresponding data are given in Table 2. It is seen that the investigated 
3-PPA have inhibiting properties at all the studied temperatures and the values of IE (\%) decreases with temperature increase. Thus, the inhibitor efficiencies were temperaturedependent and the inhibitor is being physically adsorbed at all temperatures. The values of activation energy (Ea) were determined using Arrhenius equation.

$$
\mathrm{E}_{\mathrm{a}}=2.303 \mathrm{R} \frac{\mathrm{T}_{1} \mathrm{~T}_{2}}{\mathrm{~T}_{2}-\mathrm{T}_{1}} \log \left(\rho_{2} / \rho_{1}\right)
$$

Where, $\rho_{2}$ and $\rho_{1}$ are the corrosion rates at temperatures $T_{1}$ and $T_{2}$, respectively.

Table 2. Potentiodynamic polarization parameters of mild steel in groundwater in the absence and presence of various concentrations of 3-PPA at $30-60{ }^{\circ} \mathrm{C}$

\begin{tabular}{|c|c|c|c|c|c|}
\hline $\begin{array}{c}\text { Inhibitor/ } \\
\text { Temperature }{ }^{\circ} \mathrm{C}\end{array}$ & $\begin{array}{l}\text { Inhibitor conc. } \\
\text { ppm }\end{array}$ & $\begin{array}{c}\mathrm{E}_{\text {corr, }}, \\
\mathrm{mV}\end{array}$ & $\begin{array}{c}\mathrm{i}_{\text {corr }}, \\
\mu \mathrm{A} \mathrm{cm}^{-2}\end{array}$ & $\begin{array}{l}\text { Corrosion } \\
\text { rate, mpy }\end{array}$ & $\begin{array}{c}\text { Inhibition } \\
\text { efficiency, \% }\end{array}$ \\
\hline \multirow[t]{4}{*}{ Blank at $30^{\circ} \mathrm{C}$} & - & -640 & 12.59 & 5.75 & - \\
\hline & 6 & -635 & 7.71 & 3.52 & 38.8 \\
\hline & 8 & -652 & 7.50 & 3.42 & 40.4 \\
\hline & 10 & -651 & 5.52 & 2.52 & 56.2 \\
\hline \multirow[t]{4}{*}{3 -PPA at $30^{\circ} \mathrm{C}$} & 12 & -620 & 4.26 & 1.94 & 66.2 \\
\hline & 14 & -610 & 5.31 & 2.42 & 57.9 \\
\hline & 16 & -655 & 6.36 & 2.91 & 49.5 \\
\hline & 18 & -680 & 7.12 & 3.25 & 43.4 \\
\hline \multirow[t]{4}{*}{ Blank at $40^{\circ} \mathrm{C}$} & - & -649 & 14.42 & 6.59 & - \\
\hline & 6 & -640 & 8.66 & 3.95 & 39.9 \\
\hline & 8 & -615 & 7.58 & 3.46 & 47.4 \\
\hline & 10 & -597 & 6.81 & 3.11 & 52.7 \\
\hline \multirow{4}{*}{3 -PPA at $40^{\circ} \mathrm{C}$} & 12 & -613 & 5.49 & 2.51 & 61.9 \\
\hline & 14 & -646 & 6.83 & 3.12 & 52.6 \\
\hline & 16 & -637 & 7.79 & 3.56 & 45.9 \\
\hline & 18 & -658 & 8.25 & 3.77 & 42.7 \\
\hline \multirow[t]{4}{*}{ Blank at $50^{\circ} \mathrm{C}$} & - & -635 & 16.79 & 7.67 & - \\
\hline & 6 & -580 & 10.36 & 4.74 & 38.2 \\
\hline & 8 & -550 & 8.91 & 4.07 & 46.9 \\
\hline & 10 & -523 & 8.29 & 3.79 & 50.6 \\
\hline \multirow[t]{4}{*}{3 -PPA at $50^{\circ} \mathrm{C}$} & 12 & -562 & 7.11 & 3.25 & 57.7 \\
\hline & 14 & -549 & 8.41 & 3.84 & 49.9 \\
\hline & 16 & -580 & 9.53 & 4.36 & 43.2 \\
\hline & 18 & -587 & 9.80 & 4.47 & 41.6 \\
\hline \multirow[t]{4}{*}{ Blank at $60^{\circ} \mathrm{C}$} & - & -605 & 20.12 & 9.20 & - \\
\hline & 6 & -560 & 12.46 & 5.69 & 38.1 \\
\hline & 8 & -609 & 11.27 & 5.15 & 43.9 \\
\hline & 10 & -580 & 10.36 & 4.74 & 48.5 \\
\hline \multirow[t]{4}{*}{3 -PPA at $60^{\circ} \mathrm{C}$} & 12 & -587 & 9.32 & 4.26 & 53.7 \\
\hline & 14 & -668 & 10.29 & 4.70 & 48.9 \\
\hline & 16 & -587 & 11.55 & 5.28 & 42.6 \\
\hline & 18 & -560 & 11.89 & 5.43 & 40.9 \\
\hline
\end{tabular}

The calculated values of activation energy $(E a)$ are given in Table 3 . While the higher value of the activation energy $(E a)$ of the process in an inhibitor's presence when compared to that in its absence is attributed to its physical adsorption, its chemisorptions is pronounced 
in the opposite case ${ }^{15}$. The higher value of Ea in the presence of 3-PPA compared to that in its absence and the decrease of its IE\% with temperature increase can be interpreted as an indication of physical adsorption. The protective effect as a result of Physical adsorption is due to electrostatic attraction ${ }^{16}$. In all the studied temperatures $\left(30-60{ }^{\circ} \mathrm{C}\right)$, in presence of 3-PPA the activation energy $\left(\mathrm{E}_{\mathrm{a}}\right)$ was found to be high compared with in absence of inhibitor.

Table 3. Energy of activation for the corrosion of mild steel in groundwater medium in the absence and presence of 3-PPA at different temperatures $\left(30-60^{\circ} \mathrm{C}\right)$

\begin{tabular}{cccc}
\hline \multirow{2}{*}{ Inhibitor } & \multicolumn{3}{c}{ Energy of activation $\left(\mathrm{kJmole}^{-1}\right)$} \\
\cline { 2 - 4 } & $30-40{ }^{\circ} \mathrm{C}$ & $40-50{ }^{\circ} \mathrm{C}$ & $50-60{ }^{\circ} \mathrm{C}$ \\
\hline Blank & 10.75 & 12.77 & 16.06 \\
3-PPA & 20.31 & 21.48 & 24.19 \\
\hline
\end{tabular}

\section{Conclusion}

1. The results showed that 3-PPA found to be a good inhibitor for mild steel in more corrosive water media.

2. 3-PPA suppress both anodic and cathodic reactions and hence behave as mixed type inhibitor with anodic predominant.

3. 3-Phosphonoacetic acid was temperature -dependent and their addition lead to a increase of the activation energy.

4. Studied 3-PPA was found to be physically adsorbed on mild steel surface.

5. The weight loss and polarization measurement are in reasonably good agreement.

\section{References}

1. Puckorius P R and Cunningham B, Cooling water technology advanced course, in: International Water Conference, Pittsburgh, 1997.

2. Sheir L L and Jarman R A, Corrosion, Third Ed., Butterworth-Heinmann Ltd., Great Britain, 1994.

3. Banerjee S N, An Introduction to Science of Corrosion and its Inhibition, Oxonian Press Pvt. Ltd., India, 1985.

4. Rozenfeld I L, Corrosion Inhibition, McGraw-Hill Inc., USA, 1981, 97-138.

5. Jones D A, Principles and Prevention of Corrosion, Macmillan Publishing Company, USA, 1991, 234-242.

6. Ochoa N, Baril G, Moran F and Pe'be`re N, J Appl Electrochem., 2002, 32, 497.

7. Marin-cruz J, Cabrera-Sierra R, Pech-Canul M A and Gonza`lez I, Electrochem Acta, 2006, 51, 1847-1854.

8. Gopi D, Govindaraju K M, Collins Arun Prakash V, Manivannan V and Kavitha L, J Appl Electrochem., 2009, 39, 269-276.

9. $\quad$ Flynn R W and Grourke M J, US Patent 4, 1981, 243, 316.

10. Puckorius P R and Strauss S R, Power, 1995, 5, 17.

11. Telegdi J, K'alm' an E and K'arm'an F H, Corros Sci., 1992, 33, 1099.

12. Refaey S A M, J Appl Electrochem., 1996, 26, 503-507.

13. Wehner W and Grade R, Preparation of ammonium and phosphonium salts as biocides in the protection of a variety of materials and water systems, Canadian Patent No. CA2082994, 1993, 15, 279-293.

14. Kobase S, Takerchi H and Sumita M, Antimicrobial mats containing phosphonium compounds, Japanese Patent No. JP2000316701, 2000.

15. Popova A, Sokolova E, Raicheva S and Christov M, Corros Sci., 2003, 45, 33-58.

16. Bentiss F, Traisnel M and Lagrenee M, J Appl Electrochem., 2001, 31, 41. 